\title{
Design of the three-forked-shape pedestrian landscape cable- stayed bridge with egg-shape arch tower
}

\author{
Biqing $\mathrm{Li}^{1 *}$, Jinbao $\mathrm{Li}^{1}$ and Jinfa $\mathrm{Xu}^{2}$ \\ ${ }^{1}$ Jiangsu Southeast Special Technical Engineering Co., Ltd, Nanjing, China,210008 \\ ${ }^{2}$ Jiangsu traffic engineering consulting and Supervision Co., Ltd, Nanjing, China, 211800
}

\begin{abstract}
According to the landscape requirements of the pedestrian cable-stayed bridge of the three-forkedshape canyon, this paper puts forward a kind of pedestrian landscape cable-stayed bridge with egg-shape arch bridge tower, and two kinds of spatial curve design elements are introduced, which are egg-shape arch bridge and three-forked-shape curved bridge deck. The cultural connotation of three-forked-shape canyon has been greatly improved. Combined with the actual project, the engineering parameters are designed and the Midas finite element analysis model is established, static analysis and dynamic modal analysis were carried out, it verified that the three-forked-shape pedestrian landscape cable-stayed bridge with egg-shape arch bridge tower has good mechanical performance.
\end{abstract}

\section{Introduction}

Built in 1981, the Three-forked-shape Midland Bridge in Michigan is located at the confluence of the Chippewa river and Tittabawassee river.

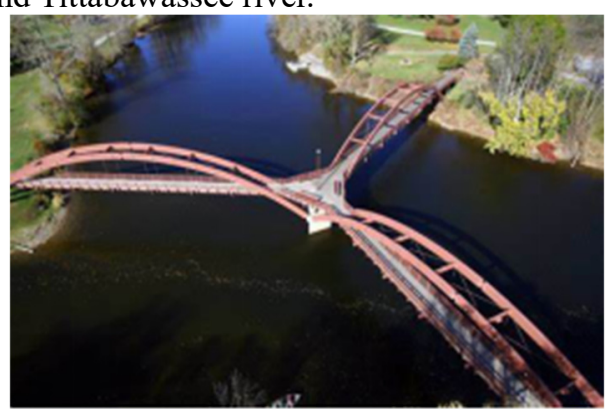

Fig.1. Midland Bridge

A special three-forked-shape bridge connects the three banks. The bridge has three branches, which lead to three different directions. Three-forked-shape bridge naturally fits in the environment and vividly illustrates the concept of unity of man and nature ${ }^{[1-3]}$.

Canyon refers to the valley with steep slope and deeper than width. At the confluence of the mainstream and tributaries of the canyon River, a fork shaped Canyon will be formed.The construction of the three-forked-shape bridge is conducive to the tourism traffic of the fork shaped canyon scenic spot.

With the development of cable-stayed bridge structure design and construction technology, people have higher and higher requirements for cable-stayed bridge landscape ${ }^{[4-6]}$. Arch steel bridge tower has been widely used because of its advantages of beautiful shape, energy saving, high efficiency and green environment protection $^{[7-10]}$.

Based on three-forked-shape canyon terrain, this paper proposes a three-forked-shape pedestrian glass bridge landscape cable-stayed bridge, the modified for eggsshape arched bridge tower cable-stayed bridge tower and bridge deck form uses annular three-forked-shape canyon, cross the bridge, the bridge the central set up a huge circular tour patio, deck stiffening girder cross-section of the stomach beam structure, bridge panel for transparent tempered laminated glass, railing for the silver metal rail. Space cable-stayed cables crisscrossed suspended glass bridge deck, forming a unique shape of three bifurcated pedestrian landscape glass cable-stayed bridge.

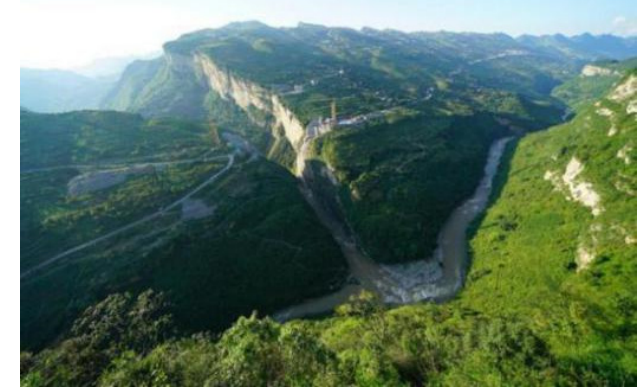

Fig.2.Three-forked-shape Canyon

In this paper, combined with the design of pedestrian glass cable-stayed bridge in three-forked-shape canyon, the paper carries out the configuration research of three fork type pedestrian landscape glass cable-stayed bridge and the engineering parameter design. The Midas finite element model was established, and carries out the dynamic modal research, so as to verify the structural superiority of the three fork pedestrian landscape glass cable-stayed bridge.

\footnotetext{
"Corresponding author:Li Biqing: umabank@163.com
} 


\section{Configuration study}

The bifurcated bridge deck of three-forked-shape canyon pedestrian glass cable-stayed bridge is composed of straight-line bridge deck and curved transition section bridge deck. The straight-line bridge deck forms $120^{\circ}$ each other. The three straight-line bridge decks are connected by arc-shaped curved transition section. A huge circular sightseeing patio is set in the center of the bridge deck, and the center point of the bridge deck is 100 meters away from the center line of the egg-shape arch bridge tower root.

Egg shape curve is an important geometric curve in mathematics. Egg curve is a symmetrical and smooth curve used in mathematics, drawing and art. Egg-shape symmetrical and smooth curve is its charm. The mathematical equation of egg shape curve is as follows:

$$
\frac{x^{2}}{a^{2}}+\frac{y^{2}}{(k y+b)^{2}}=1 \quad|k| \leq 1
$$

In the equation: $\mathrm{x}, \mathrm{y}$ are coordinate axis dimensions $\mathrm{a}$ is the egg width parameter; $\mathrm{b}$ is the egg height parameter $\mathrm{k}$ is the egg shape parameter

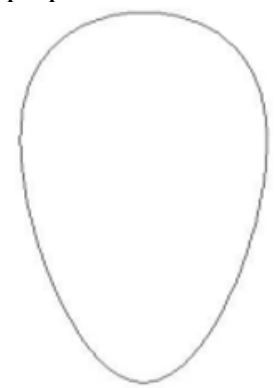

Fig.3.Geometry of Egg Curve

The traditional pedestrian landscape cable-stayed bridge structure is reformed, and the egg-shape arch bridge tower is used instead of the portal bridge tower structure, which is beautiful in shape and can improve the landscape grade of the pedestrian suspension bridge.

The arched pylon of egg-shape bridge is different from the common parabolic arch bridge tower. The lower part of the parabolic arch bridge tower is divergent and peeled outward. The lower part of the egg-shape arch bridge tower is convergent. The egg-shape arch bridge tower covers a small area, so the egg-shape arch bridge tower is very suitable for the narrow mountain landscape platform environment.

Egg-shape arched structure is beautiful, the structure is novel and light, smooth and smooth, the shape is smooth, the form is changeable, it is convenient to modify according to the actual needs, and can be widely applied to the bridge towers of various landscape bridges. threeforked-shape canyon pedestrian glass cable-stayed bridge adopts the unique egg-shape arch bridge tower, which can coordinate the scenic environment.

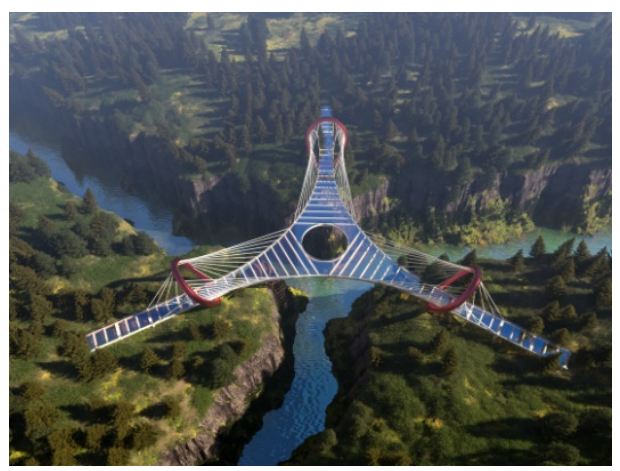

Fig.4. Cable Stayed Bridge in Three-forked-shape Canyon

With the change of bridge deck curve, the span of stiffening beam near the center circle of bridge deck is larger. Fish bellied steel beam with variable cross-section is adopted to increase the height of cross-section, but not more weight and cost. At the same time, it also enriches the bridge deck landscape viewed from the canyon.

The bridge deck is paved with toughened glass on the stiffening beam system of the bridge deck. The bridge deck is transparent and crystal clear. It is extremely dangerous and exciting to see the rapid flow of the canyon at the foot of the bridge.

The curved bridge deck with three bifurcations and the arched pylons with curved egg-shape can coordinate with the environment of three-forked-shape canyon. The architectural collocation is reasonable and the advantages are complementary. They are the ideal combination of structure and architecture.

\section{Parameter design}

The pedestrian glass cable-stayed bridge of three-forkedshape canyon is a pedestrian glass landscape cable-stayed bridge with three bifurcated bridge deck and egg-shape arch bridge tower. The horizontal distance from the center of the bridge deck to the bottom of the egg-shape arch bridge tower is 100 meters, and the span of approach bridges is 24 meters.

Egg-shape arched bridge tower adopts concrete-filled steel tube tower structure. The diameter of steel pipe is 2.5 meters, the wall thickness of steel pipe is $18 \mathrm{~mm}$, and C40 concrete is filled inside. The inclination angle of eggshape arch bridge tower is 15 degrees, the highest part is 55 meters, and the widest part of bridge tower is 40 meters. The width of the tower top in upper part section is 30 meters, the rise height is 8 meters, and the height of tower column in lower part is 47 meters. A horizontal cross bar is set everywhere Support the bridge deck.

The stay cables are scattered and anchored on the arched pylons. Each arched pylon has two groups of 11 pairs of stay cables, with a total of 66 cables. Each arched bridge tower has two groups of 5 pairs of cable-stayed cables, a total of 30 cables. The diameter of the cables varies linearly from 0.15 to $0.2 \mathrm{~m}$. The cable-stayed cables are made of 1670mpa galvanized high-strength steel wire. 


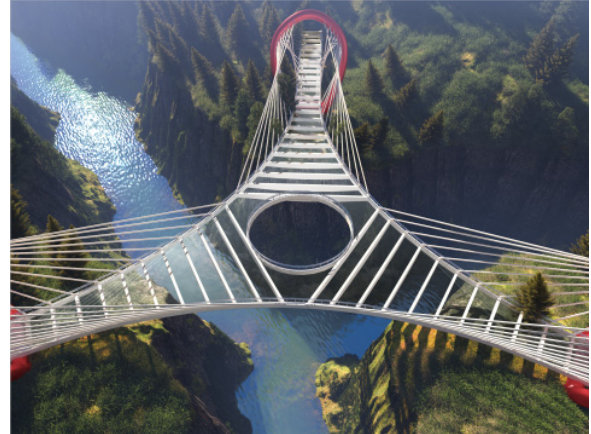

Fig.5. Stiffening Beam

The width of the bridge deck in the straight section is 15 meters, and the radius of the opening of the central patio is 20 meters. The curve sealing beam of the bridge deck changes according to the arc curve of the bridge deck, and its arc radius is 175 meters.

Steel grillage structure is adopted for the bridge deck, and the beam spacing is $8 \mathrm{~m}$. Due to the curve change of the bridge deck, the span of the stiffening beam gradually increases from the approach bridge to the center. The bridge deck stiffening beam in straight section is $15 \mathrm{~m}$ long. The stiffening beam adopts steel beam structure of rectangular steel tube. The beam width is $1 \mathrm{~m}$ and the beam section height is $2-3.5 \mathrm{~m}$. The stiffening beam of curved bridge deck is fish bellied variable cross-section steel beam. The section height of steel beam is increased to ensure the bearing capacity requirements of glass deck at midspan.

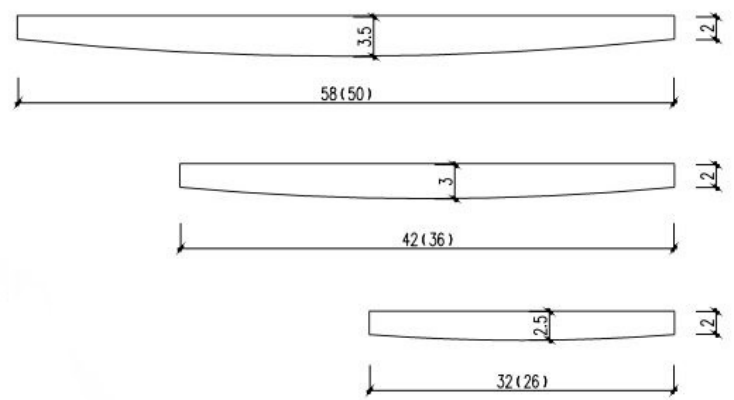

Fig.6. Fish Bellied Steel Beam

Midas model of pedestrian glass cable-stayed bridge in three-forked-shape canyon is shown in the figure below.

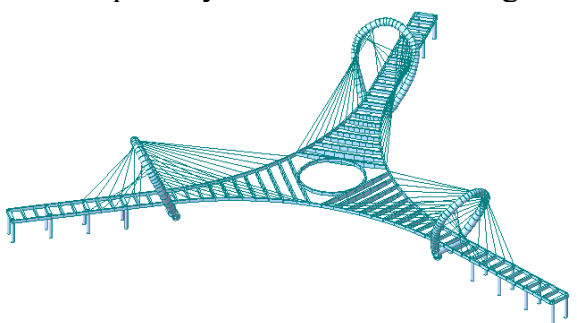

Fig.7. Midas Finite Element Model

\section{Calculation results under vertical load}

Load the main span bridge deck with full load. The standard value of uniform constant load is $5 \mathrm{kn} / \mathrm{m}^{2}$. The standard value of uniform load $4 \mathrm{kn} / \mathrm{m} 2$ is adopted for the live load of bridge deck.

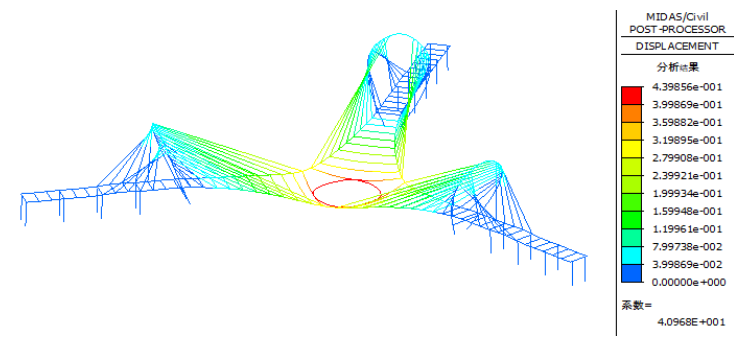

(a) Deflection

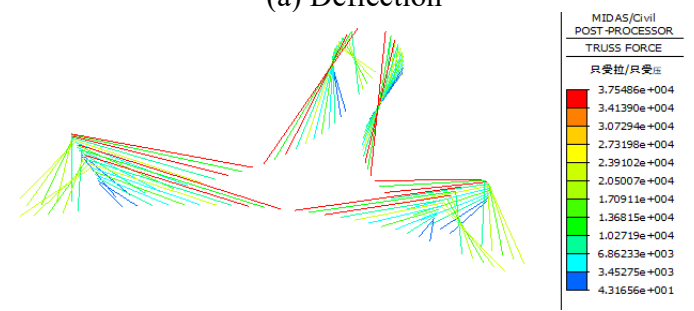

(b) Internal force of cable element

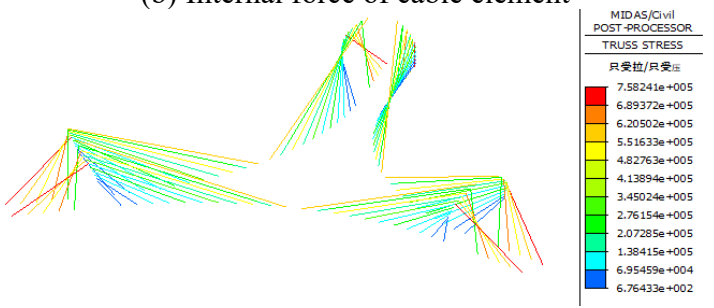

(c) Cable element stress

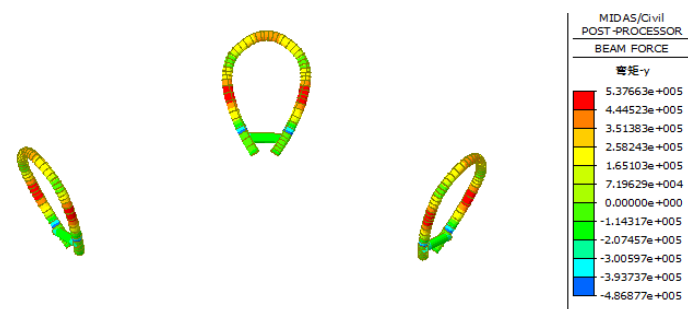

(c) Internal force of bridge tower
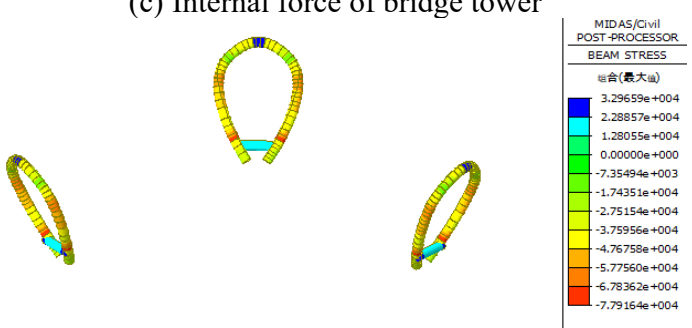

(e)Tower stress

Fig.8. Calculation Results under Vertical Load

The maximum vertical displacement occurs in the middle of the span. After deducting the form finding error of the completed bridge state, the vertical deflection under the vertical dead load is $0.224 \mathrm{~m}$, which meets the requirement of 1 / 500 limit specified in the code.

The maximum internal force of the cable is 37548.6 $\mathrm{KN}$, and the maximum stress of the cable is $758.2 \mathrm{MPa}$, which meets the strength requirements.

The maximum internal force of bridge tower is 537663 $\mathrm{KN}$, and the maximum stress of bridge tower is $77.9 \mathrm{MPa}$, which meets the strength requirements.

\section{Modal calculation results}

The main cable is the main load-bearing structure of cablestayed bridge, and the internal force of main cable and 
sling is included in the form of initial tension in dynamic characteristic analysis and modeling. Based on Midas' functions of nonlinear static analysis, stress stiffening effect and modal analysis, the natural vibration characteristics are analyzed.

In order to avoid omitting any vibration mode, the sub block method is used to solve the characteristic equation.

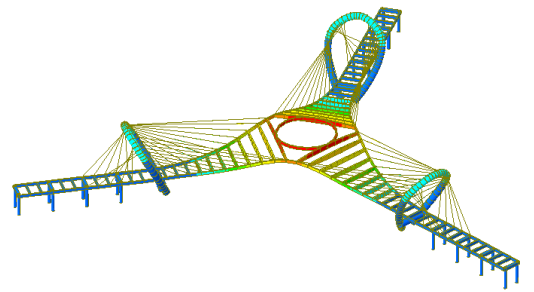

(a)first mode shape (Symmetrical vertical bending) $(0.549 \mathrm{~Hz})$

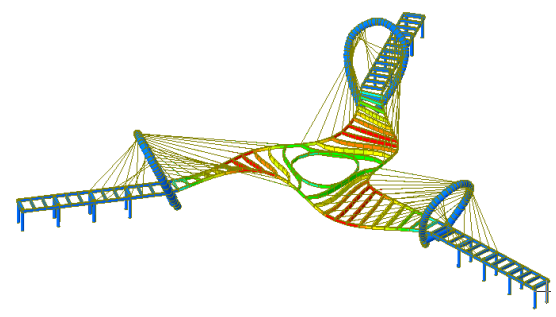

(b)The second mode shape $(0.684 \mathrm{~Hz})$

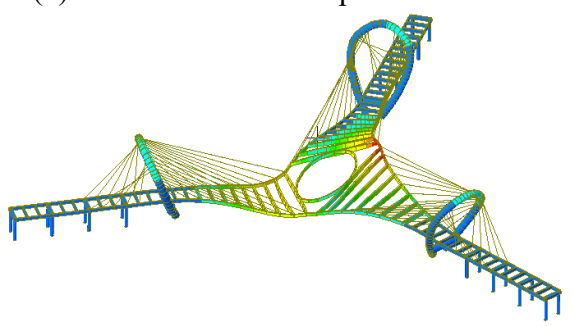

(c)The third mode shape $(0.747 \mathrm{~Hz})$

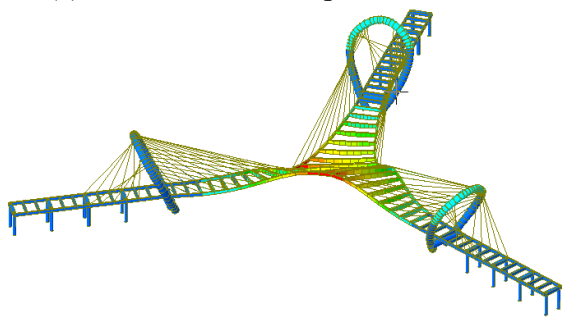

(d)The fourth mode shape $(0.747 \mathrm{~Hz})$

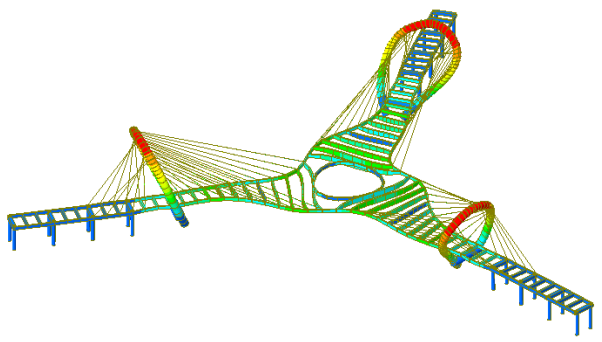

(e)The sixth mode shape $(1.112 \mathrm{~Hz})$

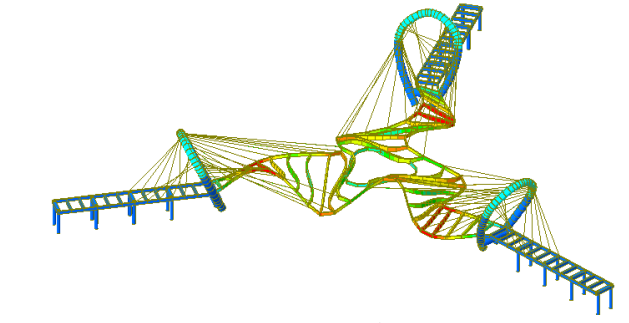

(f)The fifteenth mode shape (Bridge deck torsion) $(1.568 \mathrm{~Hz})$

Fig.9. Typical Dynamic Modal

According to the calculation results in the figure above, the first mode shape is symmetrical vertical bending, whose frequency is $0.549 \mathrm{~Hz}$; the fifteenth mode shape is bridge deck torsion, whose frequency is $1.568 \mathrm{~Hz}$.

On the whole, the vibration modes are dense, and obvious mode grouping phenomenon appears. The vibration modes are mainly vertical bending and side bending vibration, and the positive symmetric torsional vibration mode does not appear until the 15 th order. The torsion bending frequency ratio is 2.86 , which indicates that it has good wind resistance stability.

\section{Conclusion}

In this paper, taking the pedestrian landscape glass cablestayed bridge of three-forked-shape canyon as the engineering background, the paper studies the configuration of the cable-stayed bridge with three fork deck of egg-shape arch tower, establishes the Midas finite element model, carries out the static analysis under the vertical load, and carries out the dynamic modal analysis:

(1)The traditional portal cable-stayed bridge tower of cable-stayed bridge is reformed, and a new type of eggshape arch cable-stayed bridge tower is proposed. The egg-shape arch has the advantages of beautiful shape, small occupied area, convenient anchoring and dispersing cables, excellent mechanical properties and fast construction. The egg-shape arch bridge tower is very suitable for the narrow mountain landscape platform environment.

(2)The three forked pedestrian landscape glass bridge deck and egg-shape arch bridge tower match each other, and the spatial curved architectural structural elements coordinate with the environment of three-forked-shape curved Canyon, which greatly improves the cultural connotation of the scenic spot, and is the ideal combination of structure and architecture.

(3)The maximum vertical displacement occurs in the middle of the span, and the vertical deflection under the vertical live load is $0.224 \mathrm{~m}$, which meets the requirements of the code. The maximum internal force of the cable is $37548.6 \mathrm{KN}$, and the maximum stress of the cable is 758.2 $\mathrm{MPa}$, which meets the requirements of the specification.

(4)The results show that the main vibration modes are vertical bending and side bending vibration, and the positive symmetric torsional vibration mode does not appear until the 15 th order. The ratio of torsional frequency to bending frequency is 2.86 . The structure of the three bifurcated bridge is firm and the three legs stand at the same time, which has good wind stability. 


\section{References}

1. Chen Ning, Zhu Jiaqi, Li Yongle. Conceptual design and implementation of long span pedestrian cable stayed bridge in Pescara, Italy [J]. World Bridges(in China),2011(05):4-6.

2. Vladimír, Š., Michal, P., \& Tomáš, P. A Dynamic Analysis of the Cable-Stayed Footbridge in Čelákovice Town[J]. Procedia Engineering, 2017,199, 2877-2882.

3. Luo Xiaotian. Design of pedestrian landscape bridge in Nanxun Jinxiang Lake Park [J]. World bridge, 2013,41 (3): 33-37

4. Lai Yaping, Long Hao. Landscape and view: space construction of urban river crossing bridges [J]. Journal of Chongqing Jiaotong University (NATURAL SCIENCE EDITION), 2019, 38 (03): 14$20+26$

5. Yi, J., Li, J . Experimental and numerical study on seismic response of inclined tower legs of cablestayed bridges during earthquakes [J]. Engineering Structures,2019, 183, 180-194.

6. Wan Yufan, Xu Zhiqin, Zheng Lijun. Design and Construction of Wide Deck Ovate Single-pylon Cable-stayed bridge[J]. Urban Roads Bridges \& Flood Control(in China),2012(08):69-74+380.

7. Yang Shanhong, Xu Hongguang, Mei Yinghua, Wang Shengbin. Design originality of arched tower cablestayed bridge of main branch of maanshan Yangtze river bridge [J]. Highway traffic technology (applied technology version),2009,5(05):192-193.(In Chinese)

8. Wang Fan, LAI Yaping, Qiao Yunqiang, Yan Fucheng. Research on the Design of Triangular Arch Bridge tower of Hechuan Qujiang Landscape Bridge [J]. Chinese and Foreign Highways, 2008,38(02):109-112.(in Chinese)

9. Wang Ruirui, Han Da-zhang, Zhou Yanfeng.Stress analysis of steel and concrete mixing tower of Nanjing Youth Olympic Landscape Bridge [J]. Shanghai Highway, 2017,(4):21-24.(in Chinese)

10. Xu Ruifeng, LI Zheng, ZHOU Yan-feng, HAN Da-zhang.Design of steel and Mixed Section of main Tower of Nanjing Youth Olympic Landscape Bridge across the River [J]. Modern Traffic Technology, 2015,(4):38-41.(in Chinese) 